\title{
Urological complications in women with genital mutilation
}

\author{
Joao Paulo Zambon ${ }^{1 *}$, Bianca Mihai ${ }^{2}$, Cristina Alexandra Ivan ${ }^{2,3}$, Renata S Magalhaes ${ }^{3}$, Ahmet Karakeçi ${ }^{3}$ and Suzan Zhao $^{4}$ \\ ${ }^{1}$ Wake Forest University - Urology Department \\ ${ }^{2}$ Cluj Napoca County Hospital, Urology Department, Cluj Napoca, Romania \\ ${ }^{3}$ Wake Forest Institute for Regenerative Medicine, NC, USA \\ ${ }^{4}$ University of North Carolina - UNC School Medicine, Chapel Hill, NC, USA
}

\begin{abstract}
Objective: This study is a comprehensive review of literature regarding urological complications associated with female genital mutilation and its impact on women's quality of life.

Material and methods: This review encompasses articles published between 1980 and November 2016 on PubMed database. The following MeSH terms were used: "urological complications", "complications", "female genital mutilation", "female genital cutting", "female genital mutilation complications", "female genital circumcision", and "infibulation". The inclusion criteria were: English language, original articles, case reports, case series, prospective and retrospective studies, systematic reviews, and meta-analysis. Articles addressing only genital cosmetic procedures were excluded.

Results: From 1765 articles initially screened, 13 met the inclusion criteria. The overall prevalence of urological complications in women with genital mutilation is $20 \%$. Recurrent urinary tract infections, lower urinary tract symptoms, urinary retention, urogenital fistulas, meatus stenosis, urethral stones, and megaurethra are the reported ones.

Conclusions: The prevalence of urological complications is directly related to the severity of genital mutilation. Type III FGM (narrowing of the vaginal opening through the creation of a covering seal formed by cutting and repositioning through suturing the labia minora or labia majora) has the highest risk of postoperative urological complications.
\end{abstract}

\section{Introduction}

Female genital mutilation (FGM) can be defined as all procedures that intentionally alter or cause injury to the female genitalia or genital organs for non-medical reasons (World Health Organization - WHO, 2016). This spectrum of practices involves partial or total removal of the external genitalia or genital glands (greater and lesser vestibular glans) and genital organs (external clitoris) [1].

The origin of FGM is not well-known, but there are some documented reports from Greek historians suggesting that this practice started in Egypt along the Nile Valley at the time of the Pharaos. In Western Europe and the United States, clitoridectomy was described in early 50's as a therapeutic modality for perceived ailments like hysteria, epilepsy, mental disorders, masturbation, nymphomania and melancholia [2].

The WHO estimates that approximately 200 million girls/ adolescents/women worldwide are living with the harmful effects of FGM. Despite international policies as well as community-efforts to eradicate it, more than 3 million girls/adolescents are at risk of being exposed to genital mutilation every year [1].

Female genital mutilations are mostly performed on young girls by local practitioners with crude instruments (razor blades, scissors, kitchen knives, glass, sharpened rocks), without proper anesthesia, and under poor sanitation conditions. After mutilation, girls usually have their legs bounded together for a couple of weeks to "allow" scar tissue formation (Figure 1) [3-5].

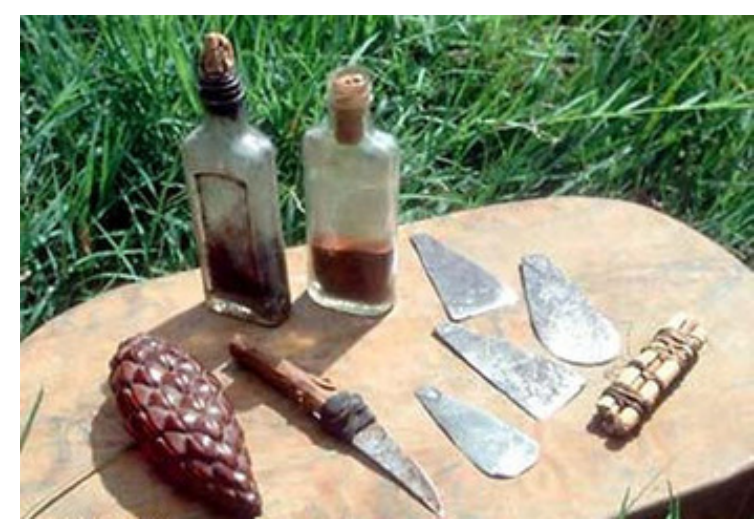

Figure 1. Crude instruments used by practitioners

In the last two decades, international organizations such as WHO, UNICEF, and United Nations Human Rights have been trying to raise the population awareness about the deleterious consequences related to genital mutilation. In some countries, a significant number of men and women has declared their support for discontinuing this practice. Nevertheless, in some African countries such as Burkina-Faso, Eritrea,

${ }^{\star}$ Correspondence to: Joao Paulo Zambon, Medical Center Boulevard, WinstonSalem, NC, 27103, USA, E-mail: jzambon@wakehealth.edu

Received: February 26, 2018; Accepted: March 09, 2018; Published: March 12 2018 
Sudan, Sierra Leone, Mali, and Somalia the prevalence of FGM remains greater than $75 \%[3]$.

Short and long-term consequences of genital mutilation to women's life are poorly reported in the literature. Most likely because this population has limited access to healthcare system and most genital mutilated women fell constraint to disclose their symptoms due to sensitive nature of this issue [6,7].

This study is a comprehensive review of literature regarding urological complications associated with female genital mutilation and its impact on women's quality of life.

\section{Material and methods}

This review encompasses articles published between 1980 and November 2016 on PubMed database. The following MeSH terms were used: "urological complications", "complications", "female genital mutilation", "female genital cutting", "female genital mutilation complications", "female genital circumcision", and "infibulation".

The inclusion criteria were: English language, original articles, case reports, case series, prospective and retrospective studies, systematic reviews, and meta-analysis. Articles addressing only genital cosmetic procedures were exclude.

\section{Study Design}
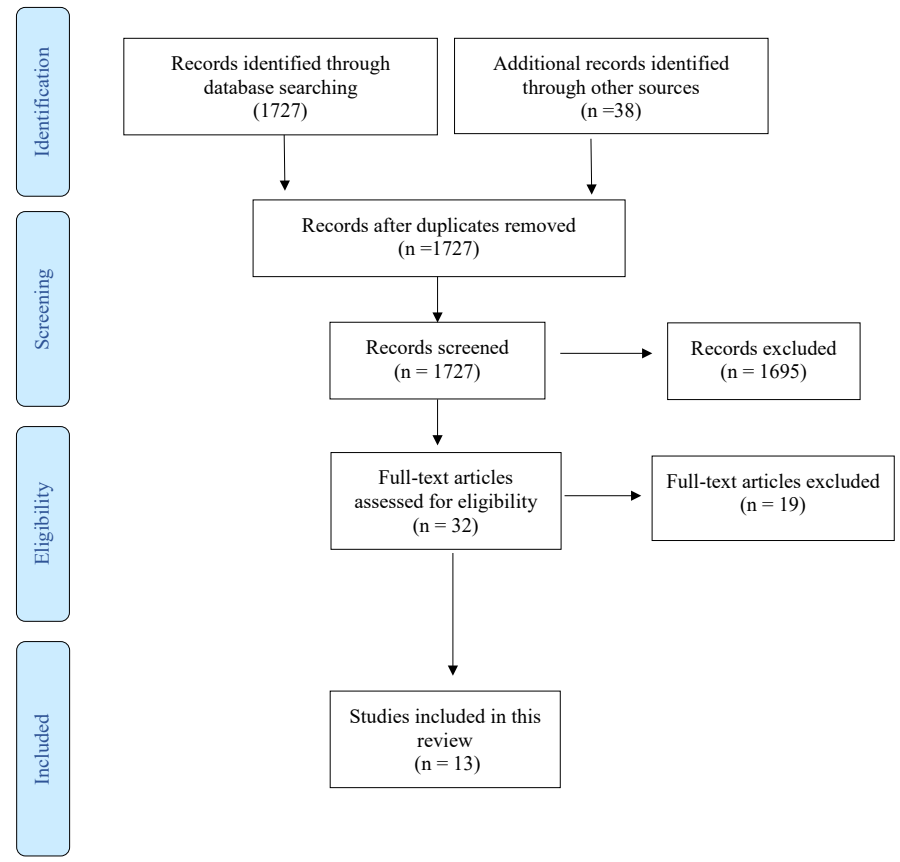

\section{Classification of female genital mutilation}

FGM - WHO classification (Figure 2) [8]

- Type I - "clitoridectomy"- prepuce excision with/without partial or total removal of the clitoris.

Type Ia - removal of the clitoral hood or prepuce only.

Type Ib - removal of the clitoris with the prepuce.

- Type II - "excision"- partial or total removal of the clitoris and the labia minora, with or without labia majora.

Type IIa - removal of the labia minora only.



Type IIb - partial or total removal of the clitoris and the labia minora.

Type IIc - partial or total removal of the clitoris, the labia minora and the labia majora.

- Type III - narrowing of the vaginal opening through the creation of a covering seal formed by cutting and repositioning through suturing the labia minora or labia majora (infibulations).

Type IIIa - removal and apposition of the labia minora.

Type IIIb - removal and apposition of the labia majora.

- Type IV - all other procedures as pricking, piercing, incising, scraping and cauterizing the genital area.

WHO classification takes into account a detailed description of female genital anatomy; however, in some cases women's genital appearance may not fit into any category. To overcome this issue, UNICEF proposed another classification that is less accurate regarding anatomy, but easier to understand and define than WHO classification.

\section{FGM - UNICEF classification [9]}

- Type I - "Cut, no flesh removed" ("nickling” or "pricking”, which corresponds to WHO Type IV).

- Type II - "Cut, some flesh removed" (corresponds to WHO Type I and II).

- Type III - “Sewn closed” (corresponds to WHO Type III).

- Type IV - Not determined.

\section{Results}

From 1765 articles initially screened, 32 full-text articles were assessed for eligibility, and 13 met the inclusion criteria: 9 crosssectional studies, 2 case reports, 1 case-control, and 1 describing a retraction technique for self-catheterization.

\section{Urological complications related to FGM}

The overall prevalence of urological complications in genital mutilated women ranges from 20 to $30 \%$. The most prevalent complications reported in the literature are: 1) Recurrent urinary tract infections (UTI); 2) Lower urinary tract symptoms (LUTS); 3) Urinary retention; 4) Urogenital fistula; 5) Meatus stenosis and urethral stone; and 6) Megaurethra. 


\section{Recurrent urinary tract infections}

The prevalence of recurrent UTI in women underwent Type I genital mutilation was $10 \%$, whereas in Type III is up to $30 \%$. Three studies demonstrated a correlation between severity of FGM and prevalence of recurrent UTIs. Patients underwent Type III FGM (narrowing of the vaginal opening through the creation of a covering seal formed by cutting and repositioning through suturing the labia minora or labia majora) or Type IV FGM (all other procedures as pricking, piercing, incising, scraping and cauterizing the genital area) were more prone to develop recurrent UTIs. In these cases the etiology is bladder outlet obstruction and incomplete bladder emptying [10-12].

\section{Lower urinary tract symptoms (LUTS)}

There are two studies in the literature addressing LUTS women underwent genital mutilation. In a case control study that enrolled 251 cases and 183 controls, day and night-time frequency as well as urgency were associated with FGM. Intermittent urinary stream and incomplete bladder emptying were reported by $20 \%$ of mutilated women. Terminal dribbling, urinary straining, and weak stream were reported by 19,13 , and $10 \%$ of women respectively [13].

Agugua et al studied 290 Somali women between 18 and 54 years of age who underwent FGM earlier in their life. From 290 women, 255 underwent infibulation, 18 clitoridectomy, and 17 excisions of the prepuce only. Infibulations (narrowing of the vaginal opening through the creation of a covering seal formed by cutting and repositioning through suturing the labia minora or labia majora) increased the likelihood of short and long-term voiding symptoms such as incomplete bladder emptying and weak urinary stream. Due to a small sample of patients the association of clitoridectomy and prepuce excision and LUTS is inconclusive [14].

\section{Urinary retention}

Urinary retention following FGM is multifactorial: 1) Local practitioners do not have knowledge regarding anatomy and physiology of the female urogenital tract; 2) It is commonly performed without anesthesia and therefore is a painful and traumatic experience; 3) Psychological impact on women's quality of life is not a major concern for those practitioners; 4) Post-procedure genital swelling difficulty emptying the bladder [15-18].

\section{Urogenital fistula}

The prevalence of urogenital fistula in the literature in mutilated women ranges from 10 to $15 \%$. The risk factors for post-procedure urogenital fistula formation are: 1) Lack of anatomical knowledge by local practitioners; 2) Use of non-sterilized crude instruments; 3) Urogenital infection; 4) Scar tissue formation and healing by second-intention; 5) Bladder outlet obstruction; 6) Vaginal stenosis; 7) Traumatic sexual intercourse; 8) Prolonged labor due to vaginal stenosis; 9) Poor assistance for either vaginal or C-section delivery.

Women underwent infibulations (narrowing of the vaginal opening through the creation of a covering seal formed by cutting and repositioning through suturing the labia minora or labia majora) are at the highest risk of post-procedure fistula formation because labia majora and/or minora closure predispose these women to hematocolpos. Thus, chronically it increases the risk of infection, drainage, and urogenital fistula. The most common clinical complaints in these cases are urinary incontinence, dyspareunia, chronic pelvic pain, and recurrent UTI [19-22].

\section{Meatus stenosis}

There is one study in the literature describing a retraction technique for self-catheterization in women with infibulation who developed vaginal and urethral meatus stenosis. Toubia studied 162 mutilated women from 6 African countries: Chad, Egypt, Eritrea, Ethiopia, Somalia, and Sudan. All of them had vaginal and urethral meatus stenosis and emptied their bladder doing self-catheterization. In this study, the most severe cases required a retraction technique to visualize and catheterize the retracted urethral meatus [23].

\section{Urethral stone}

There is one case report of a 32-years old Somali woman who had been infibulated earlier in her life and presented with dyspareunia, dysmenorrhea, and chronic pelvic pain. A urethral stone measuring $0,8 \mathrm{~cm}$ was accidentally found during defibulation and labia majora reconstruction [24].

\section{Megaurethra}

There is one a case report of a 21-years old woman with Type III genital mutilation who developed megaurethra due to repetitive urethral coitus [25].

\section{Discussion}

Female genital mutilation is a devastating condition that affects women's integrity and violates the basic principle of human rights. The procedure by itself is always traumatic and has no health benefits. For the last two decades, international organizations have been doing a significant work to aware the population about the risks inherent to this procedure. There is a lack of studies in the literature addressing specifically urological complications in women underwent genital mutilation. The most prevalent urological reported in the literature are: 1) Recurrent UTIs; 2) Lower Urinary Tract Symptoms due to bladder outlet obstruction; 3) Urinary retention, and 4) Urogenital fistula. All urological complications were more prevalent in Type III FGM (narrowing of the vaginal opening through the creation of a covering seal formed by cutting and repositioning through suturing the labia minora or labia majora) [8].

Urinary tract infections and LUTS occurs due to long-term bladder outlet obstruction. Over the years, these women tend to develop bladder with impaired or even acontractility leading to incomplete bladder emptying, chronic urinary retention, and paradoxical urinary incontinence. As many mutilated women do not feel comfortable to address this issue with urologists and/or gynecologists, a physical exam and ultrasonography are highly recommended in all cases [1].

The main risk factors associated with post-procedure complications are the lack of knowledge of anatomy and physiology of female urogenital tract and the poor sanitation conditions in which the procedure is routinely performed. Regarding quality of life, the most deleterious complication is the urogenital fistula. The narrowing or closure of the vaginal canal increase the likelihood of hematocolpos. Thus, most of them develop genital infections, urinary incontinence, chronic pelvic pain, dysmenorrhea, and urogenital fistulas. Up to $80 \%$ of these women reported poor sexual life related to physical and psychological issues $[25,26]$.

We believe that international policies associated with raising awareness of the population in regard to the harmful consequences of any type of genital mutilation are important steps toward its eradication. Besides of that, we understand that complete eradication is still far from the reality. Continuous effort by healthcare professionals to disclose the 
procedure-related risks along with regulation measures acknowledged and developed by worldwide organizations are necessary to increase the hope and shed some light for this specific subset of patients [27-32].

\section{Conclusions}

The prevalence of urological complications in women with genital mutilation is directly related to the severity of the procedure. Type III FGM is the most deleterious type because of the inherent risk of vaginal stenosis, hematocolpos, and urogenital fistula. The prompt recognition and evaluation of these women are advised for healthcare professionals aiming to provide dignity and quality of life for these women.

\section{References}

1. World Health Organization guidelines on the management of health complications from female genital mutilation (2016) World Health Organization 1-47.

2. Odukogbe, Afolabi, Bello, Adeyanju (2017) Female genital mutilation/cutting in Africa. Transl Androl Urol 6: 138-148. [Crossref]

3. Michael MM, Moneti F, Lewnes A, et al. (2005) Changing a harmful social convention: female genital mutilation/cutting. Florence, Italy: UNICEF Innocenti Research Centre.

4. Wakabi W (2007) Africa battles to make female genital mutilation history. Lancet 369: 1069-1070. [Crossref]

5. Clarke E (2016) Female genital mutilation: a urology focus. Br J Nurs 25: 1022-1028. [Crossref]

6. Female genital mutilation/cutting (2013) A statistical overview and exploration of the dynamics of change. New York: UNICEF; 2013.

7. Eliminating female genital mutilation: An interagency statement UNAIDS, UNDP, UNECA, UNESCO, UNFPA, UNHCHR, UNHCR, UNICEF, UNIFEM, WHO (2008) World Health Organization Library 1-48.

8. Obermeyer CM (1999) Female genital surgeries: the known, the unknown, and the unknowable. Med Anthropol $Q$ 13: 79-106. [Crossref]

9. Talle A (1993) Transforming women into 'pure' agnates: aspects of female infibulation in Somalia. In: Broch- Due V, Rudie I, Bleie T, eds. Carved flesh, cast selves: gender symbols and social practices. Oxford Berg 83-106.

10. Berg RC, Odgaard-Jensen J, Fretheim A, Underland V, Vist G (2014) An updated systematic review and meta-analysis of the obstetric consequences of female genital mutilation/cutting. Obstet Gynecol Int doi: 10.1155/2014/542859.

11. Reisel D, Creighton SM (2015) Long term health consequences of Female Genital Mutilation (FGM). Maturitas 80: 48-51. [Crossref]

12. Classification of Female Genital Mutilation. 2007.

13. UNICEF. Female genital mutilation/cutting. A statistical overview and exploration of the dynamics of change. 2013. (www.unicef.org) http://www.unicef.org/media/files/ FGCMLores.pdf

14. Agugua NE, Egwuatu VE (1982) Female circumcision: management of urinary complications. J Trop Pediatr 28: 248-252. [Crossref]

15. Shandall AA (1967) Circumcision and infibulation of females: a general consideration of the problem and a clinical study of the complications in Sudanese women. Sudan Med J 5: 178-212. [Crossref]
16. Almroth L, Bedri H, Musharaf S, Satti A, Idris T, et al. (2005) Urogenital complications among girls with genital mutilation: a hospital-based study in Khartoum. Afr J Reprod Health 9: 118-124. [Crossref]

17. Amin MM, Rasheed S, Salem E (2013) Lower urinary tract symptoms following female genital mutilation. Int J Gynaecology Obstr 123: 21-23. [Crossref]

18. Dirie MA, Lindmark G (1992) The risk of medical complications after female circumcision. East Afr Med J 69: 479-482. [Crossref]

19. National Institute of Stastic, Economic and Demographic Studies (INSEED) (2005) Ministry of the Economy, Planning and Co-operation, ORC Macro. Demographic and Health Survey Chad 2004. Calverton, Maryland: INSEED, ORC Macro.

20. Ministry of Economy, Planning and International Cooperation, Macro International Inc. (1995) Demographic and Health Survey, Central African Republic 1994-95. Calverton, Maryland: Demographic and Social Statistics Branch, Macro International Inc.

21. El Dareer A (1983) Complications of female circumcision in the Sudan. Trop Doct 13: 131-133. [Crossref]

22. Rushwan H, Slot CJM, E Dareer A, et al. (1983) Female circumcision in the Sudan Prevalence, complications, attitudes and change. A report of a study conducted by the faculty of medicine, University of Khartoum, Sudan Khartoum: University of Khartoum.

23. Toubia N (1994) Female circumcision as a public health issue. $N$ Engl J Med 331 712-716 [Crossref]

24. Ampofo K, Otu T, Uchebo G (1990) Epidemiology of vesico--vaginal fistulae in northern Nigeria. West Afr J Med 9: 98-102. [Crossref]

25. Mabeya HM (2004) Caracteristics of women admitted with obstetric fistula in rural hospitals in West Pokot, Kenya. Geneva: Geneva Foundation for Medical Education and Research.

26. Maheu-Giroux M, Filippi V, Maulet N, Samadoulougou S, Castro MC, et al. (2016) Risk factors for vaginal fistula symptoms in Sub-Saharan Africa: a pooled analysis of national survey data. BMC Pregnancy Childbirth 16: 82.

27. Abdulrahim A Rouzi, Nora Sahly, Nedaa Bahkali, Hassan Abdulijabbar (2013) Retraction technique for urinary catheterization of women with female genital mutilation. European Journal of Obstetrics \& Gynecology and Reproductive Biology 169: 296-298. [Crossref]

28. Nour, Nawal M (2006) Urinary Calculus Associated with Female Genital Cutting. Obstetrics \& Gynecology 107: 521-523. [Crossref]

29. Deniz A, Ozan B, Omer D, Adil E (2015) A complication of female circumcision: Vaginal Stenosis and Total Incontinence Due to Urethral Intercourse. J Urol Surg 2 91-93.

30. Landry E (2013) Profiles and experiences of women undergoing genital fistula repair: findings from five countries. Glob Public Health 8: 926-42. [Crossref]

31. Eliminating female genital mutilation: an interagency statement UNAIDS, UNDP, UNECA, UNESCO, UNFPA, UNHCHR, UNHCR, UNICEF, UNIFEM, WHO (2008) World Health Organization Library. 1-48.

32. WHO study group on female genital mutilation and obstetric outcome, Banks E, Meirik O, Farley T, Akande O, Bathija H, Ali M (2006) Female genital mutilation and obstetric outcome: WHO collaborative prospective study in six African countries. Lancet 367: 1835-1841. [Crossref]

Copyright: $@ 2018$ Zambon JP. This is an open-access article distributed under the terms of the Creative Commons Attribution License, which permits unrestricted use, distribution, and reproduction in any medium, provided the original author and source are credited. 